\title{
Model to Predict Failure Time for FRP Reinforced Concrete Structures under Extreme Heat
}

Faruqi MA* and Garcia L

Department of Civil Engineering, MSC 194, Texas A \& M University, Kingsville, TX, USA

\begin{abstract}
The use of fiber-reinforced polymer (FRP) as a reinforcing agent in concrete structures has created an increased interest in recent years. However, the behavior of such members in fire is still relatively unknown. This is the main reason limiting the widespread use of FRP in buildings. A reliable model is needed to aid designers towards the prediction of failure time of FRP reinforced concrete structures exposed to fire based on the service moment. Therefore, the main of goal of this paper is to develop a model that can predict the failure time of FRP reinforced concrete structures exposed to fire based on the moment capacity. American Concrete Institute $(\mathrm{ACl})$ design codes designated for the flexural and shear strength of reinforced concrete were used as a basis for creating this model. Failure time of FRP reinforced structure under fire was obtained from literature. The moment capacity of the literature structure was calculated and was used to predict the failure time using our model. It was found that our model predicted the failure time within $20 \%$ of the time obtained from literature.
\end{abstract}

Keywords: FRP; Structures; Strength; Resin; Glass transition temperature

\section{Introduction}

Deterioration of infrastructure resulting from corrosion of steel reinforcement in concrete has led to the use of fiber-reinforced polymer (FRP) composites as an alternative. High strength to weight ratio and corrosion resistance of FRP rebars provides a significant advantage over steel [1]. FRP reinforcement is used in bridges, multi-storied buildings, industrial structures and parking garages to name a few.

The design behavior of FRP reinforced concrete structures is well known at ambient temperatures [2-4]. However, its behavior at elevated temperatures is quite complex and as a result codes do not specify any fire guidelines.

The American Concrete Institute (ACI) code merely recommends that FRP reinforced concrete structures must meet all building and fire code requirements that apply to a typical reinforced concrete structure [4]. The British Standard BS 476 [5] and BS 9999 [6] consider deflection and structural fire resistance as factors to determine beam failure.

At higher temperatures, the concrete gets de-moisturized rapidly and produces cracks. This cause the FRP rebars to burn and eventually de-bond [7]. Thermo-mechanical behavior of FRP rebars depends on the polymer behavior of FRP rebar depends on the polymer resin [7]. The polymer resin will soften and the FRP bar reaches its glass transition temperature rapidly. Elastic modulus (E-modulus) of the polymer decreases significantly when the temperature reaches and exceeds glass transition temperature [7]. The glass transition region is the most significant practical region of FRP for design purposes. This is because the system undergoes significant plastic deformations beyond this region resulting in structural collapse [8-10]. At this transition temperature, the resin is no longer able to transfer stresses from concrete to fibers. This leads to increased crack widths, deflections, and eventual failure of structure. Unfortunately, this topic has received very little attention from the research community.

Therefore, in order to advance the topic, this paper attempts to develop a model that can predict the failure time of FRP reinforced concrete structures exposed to fire based on the moment capacity.

\section{Assumptions, caveats and limitations}

Design codes outlined in ACI 440 [2] provide the basic equations that are used to predict the behavior of rectangular concrete beams reinforced with FRP. If the service loads and dimensions are provided, the strength characteristics that will resist failure of the beam can be determined. Although many strength parameters and concrete structures can be analyzed, this work has focused on the flexural capacity of concrete beams with a rectangular cross section. This model, however, is not intended to provide a design strength to resist loads, but rather an estimate at what time FRP reinforced concrete will fail when exposed to fire conditions.

In order for this model to be reliable, investigation into the thermal properties of FRP is required. Therefore, it is necessary to know how the strength of FRP changes with time and temperature increase. The variance of these thermal properties with time as temperature increases is vital to the creation of the model. A series of previous experiments [11] provided the necessary data that showed the changes in properties of FRP with temperature. That data was used to create the model that predicted failure time.

The behavior of unreinforced concrete under extreme heat is also considered in order to determine the reduction in strength with time. This allows for the model to strive for a simultaneous failure condition as opposed to the time at which only the FRP rebars will fail. The model uses the design codes to provide the basic equations regarding minimum reinforcing ratios for simultaneous failure.

\section{Scope}

This paper attempts to create a model that will most accurately predict the failure time of FRP reinforced concrete structures under fire conditions. By modifying the cross sectional reinforcing ratio, two failure states can be examined: failure in the reinforcing bar and failure

*Corresponding author: Faruqi MA, Department of Civil Engineering, MSC 194, Texas A\&M University, Kingsville, TX, USA, Tel: (361)-593-2271, E-mail: m-faruqi@tamuk.edu

Received June 14, 2017; Accepted January 15, 2018; Published January 19, 2018

Citation: Faruqi MA, Garcia L (2018) Model to Predict Failure Time for FRP Reinforced Concrete Structures under Extreme Heat. J Civil Environ Eng 8: 294 doi: 10.4172/2165-784X.1000294

Copyright: @ 2018 Faruqi MA, et al. This is an open-access article distributed under the terms of the Creative Commons Attribution License, which permits unrestricted use, distribution, and reproduction in any medium, provided the original author and source are credited. 
by crushing of concrete. This allows for the individual stress experienced by each material to be calculated.

By experimentation, the variance of the modulus of elasticity with time as temperature increases is known [11]. This critical change in the modulus of elasticity of FRP was essential in determining the stress at failure and allowed for a link to be established between the change in material properties, corresponding stress, and strength capacity. Once the stress at failure for both materials is known, the corresponding moment capacity can be calculated. This resulted in the creation of two models: one when the FRP rebar failure occurs first and the other when the concrete fails first. An analysis of accuracy is later discussed.

\section{Research significance}

If an accurate model to predict the failure time of FRP reinforced concrete is implemented, then designers and fire safety entities will have a greater understanding of how to prepare for and react to emergencies. Although the data used for this model was obtained from controlled experiments, fires in actuality rarely exhibit a contained behavior or predictable temperature. However, the time to failure obtained from the model gives us a greater understanding of how FRP reacts under fire conditions.

\section{Methodology}

The cross sectional area ratio of FRP to concrete in the beam is modified to produce two types of failure. The reinforcement ratio is named $\delta$, where $\delta=\mathrm{A}_{\text {frp }} / \mathrm{A}_{\text {beam }}$

The cross sectional area of the beam is calculated from the nominal depth $\mathrm{d}$ and the width of the beam w. ACI 440 [2] has established the minimum reinforcing ratio for FRP reinforced concrete under normal conditions. If the reinforcing ratio is set too low, then failure will first occur in the reinforcement. Any ratio above the minimum established by the code will assure that failure occurs by the crushing of concrete. Research and testing performed on the material properties of FRP [12] has revealed that when the material is under tensile loading, the transition from the elastic behavior to the ultimate stress is relatively short. This indicates that FRP appears to have no "yielding" state. This sudden failure condition, coupled with the change in material properties of FRP at elevated temperatures, and the brittle nature of concrete makes establishing a simultaneous failure ratio difficult.

An expression is created to describe the state when the reinforcement ratio is lower than the established limit and the FRP will fail first. This expression, utilizes the modulus of elasticity and the established concrete failure strain taken from the code [13]. The stress in the concrete at this state is provided by the following equation:

$$
\sigma_{\text {conc. }}=\frac{1}{2} \sigma_{f r p} \delta+\frac{1}{2} \sigma_{f r p} \delta \sqrt{1+\frac{4 E_{\text {conc }}}{\delta E_{f r p}}}
$$

The stress in the reinforcement at failure can be found by increasing the reinforcing ratio such that failure occurs in the concrete. At this state, the stress in the FRP reinforcement is provided by the following expression:

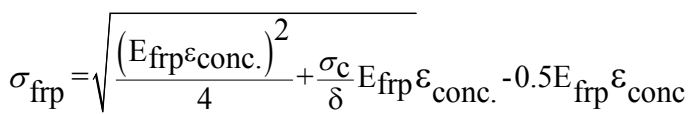

The previous equations allow for the corresponding stress in the FRP and concrete at failure sates. When the beam is exposed to fire and the temperature begins to increase, the potential failure states begin to change. We can assume that as the temperature increases, a FRP reinforced beam that would have failed by crushing of concrete will now fail by reinforcement failure due to the breakdown of the FRP resin. Because of this change in failure modes, two equations result from the respective failure state stresses to produce the flexural capacity of the beam in each state. Equation 2a indicates where the concrete will fail first and equation $2 b$ indicates where the rebar will fail first.

$$
\begin{aligned}
& M_{\mathrm{n} @ \text { conc.failure }}=\mathrm{d}^{2} \mathrm{w}\left[\delta \sigma_{\mathrm{frp}}^{*}-\frac{\left(\delta \sigma^{*} \mathrm{frp}\right)^{2}}{\sigma_{\text {conc. }}^{-}}\right] \\
& M_{\mathrm{n} @ \text { rebar failure }}=\mathrm{d}^{2} \mathrm{w}\left[\delta \sigma_{\text {frp }}^{*}-\frac{\left(\delta \sigma^{-} \text {frp }\right)^{2}}{\sigma^{*} \text { conc. }}\right]
\end{aligned}
$$

Where:

$\sigma_{\text {frp }}^{\star}=$ Stress in FRP reinforcement at concrete failure state

$\sigma_{\text {frp }}^{-}=$Strength of FRP reinforcement at failure temperature

$\sigma_{\text {conc. }}^{*}=$ Strength of concrete at particular failure state

$\sigma_{\text {conc. }}^{-}=$Strength of concrete at failure temperature

$\mathrm{d}=$ Nominal depth of rectangular beam

$\mathrm{w}=$ Width of beam

$\varepsilon_{\text {conc }}=$ Concrete strain at failure $\sim 0.30 \%$

$\mathrm{E}_{\text {frp }}=$ Modulus of elasticity of FRP reinforcement @ $\mathrm{T}^{\circ} \mathrm{C}$

$\mathrm{E}_{\text {conc. }}=$ Modulus of elasticity of concrete @ $\mathrm{T}^{\circ} \mathrm{C}$

The equations for the flexural capacity above are used to calculate the changing moment capacity as time increases. Experiment performed on a rebar specimen exposed to heat [14] reported the change in properties of the rebar with respect to time and not temperature. The reported strength reduction factors [14] based on the changing modulus of elasticity makes the model time sensitive. The strength $(\sigma)$ and stiffness (E) reduction factors used for different concrete cover thicknesses are as follows:

$\mathrm{K}_{\sigma}=1-0.007 \mathrm{t}$ for $105 \mathrm{~mm}$ cover

$\mathrm{K}_{\sigma}=1-0.00073 \mathrm{t}$ for $70 \mathrm{~mm}$ cover

$\mathrm{K}_{\sigma}=1-0.01 \mathrm{t}$ for $30 \mathrm{~mm}$ cover

$\mathrm{K}_{\mathrm{E}}=1-0.0044 \mathrm{t}$ for $105 \mathrm{~mm}$ cover

$\mathrm{K}_{\mathrm{E}}=1-0.0046 \mathrm{t}$ for $70 \mathrm{~mm}$ cover

$\mathrm{K}_{\mathrm{E}}=1-0.0063 \mathrm{t}$ for $30 \mathrm{~mm}$ cover

According to Bailey [15] concrete alone suffers a reduction in strength when exposed to fire. An effect known as spalling occurs when concrete is exposed to elevated temperatures. Although extensive research into the causes and predictability of spalling has been carried out, very few convincing conclusions have been made. When a concrete beam is exposed to extreme heat three types of spalling can occur; corner spalling, aggregate spalling, and explosive spalling. Corner spalling does not typically decrease the strength of the beam, as it remains sound where most of the loads are concentrated. Aggregate spalling is purely superficial damage and occurs when pieces of the concrete fly off the surface due to aggregate rupture. Explosive spalling exhibits complete 
destruction and failure and is the cause for most concern. Abbasi and Hogg [14] presented an empirical approach that describes the change in the concrete compressive strength with time. It is presented as a reduction factor:

$$
\mathrm{K}_{\mathrm{c}}=1-0.0031 \mathrm{t}
$$

\section{Model application}

The model to predict the failure time of FRP reinforced beams was applied as a method of comparison to a previous test [16] performed on FRP reinforced beams. Abassi and Hogg [16] reported that two beams $350 \mathrm{~mm}$ wide, $400 \mathrm{~mm}$ deep and with a span of $4.25 \mathrm{~m}$ sustained an applied load of $40 \mathrm{kN}$ at mid-span. The reinforcement ratio $\delta$, was set to ensure failure by concrete crushing at 0.0089 . The diameter of the FRP rebar used was $12.7 \mathrm{~mm}$. The cross section of the beam is shown in Figure 1. The particular beam of interest for this work is beam 1 from the experiment, because the stirrups used in the beam were steel. This configuration isolated the flexural capacity of the FRP rebar while the configuration for Beam 2 used FRP stirrups to analyze the shear strength of the beam. Abbassi and Hogg report that the failure time for beam 1 was 128 minutes and 94 minutes for beam 2 .

The model of this work which is summarized in equations $2 \mathrm{a}$ and $2 \mathrm{~b}$, was applied using the dimensions of the beam tested by Abbassi and Hogg [16]. The applied service moment is calculated as: density)

Beam weight $=($ cross-sectional area $) \times($ length of beam $) \times($ concrete

$$
\begin{aligned}
& =(0.35 \times 0.40)(4.25)\left(23 \mathrm{kN} / \mathrm{m}^{3}\right) \\
& =13.7 \mathrm{kN} / 4.25 \mathrm{~m}=3.22 \mathrm{kN} / \mathrm{m}
\end{aligned}
$$

Point load $=40 / 4.25=9.4 \mathrm{kN} / \mathrm{m}$

Total Service Load $=9.4+3.22=12.62 \mathrm{kN} / \mathrm{m}$

Service moment $=(\mathrm{w})\left(\mathrm{L}^{2}\right) / 8=12.62\left(4.25^{2}\right) / 8=28.5 \mathrm{kN}-\mathrm{m}$

The service moment applied to the beam is $28.5 \mathrm{kN}-\mathrm{m}$. This moment indicates the "failure point" at which the capacity is less than the service load. The generalized moment capacities due to concrete and rebar failure were calculated using equations $2 \mathrm{a}$ and $2 \mathrm{~b}$ and shown in Figure 2 . At this moment of $28.5 \mathrm{kN}$-m the FRP reinforced beam experiences failure. The figure shows the failure of beam 1 occurs at 152 minutes based on our model. The model is considered to be reasonable as it is

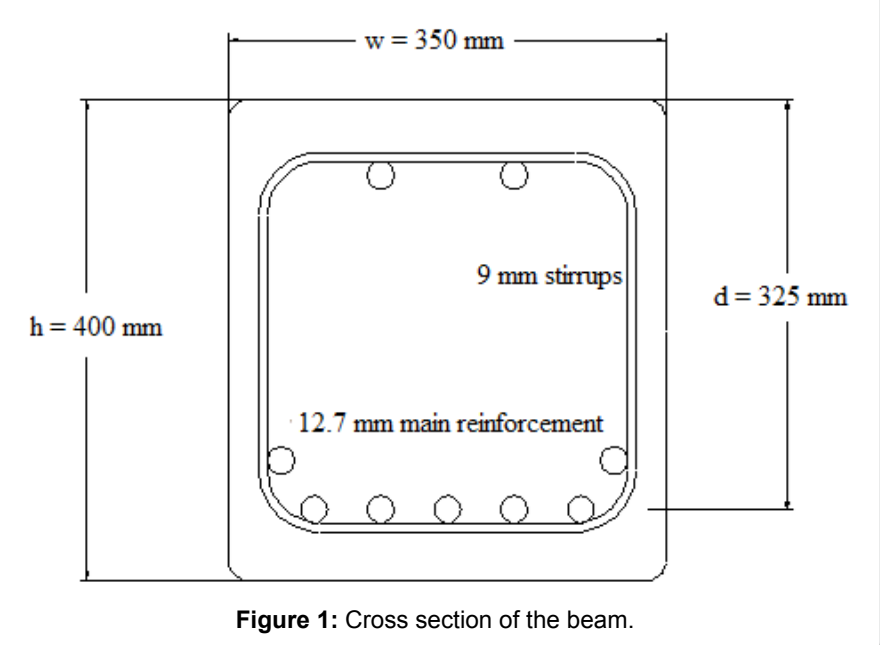

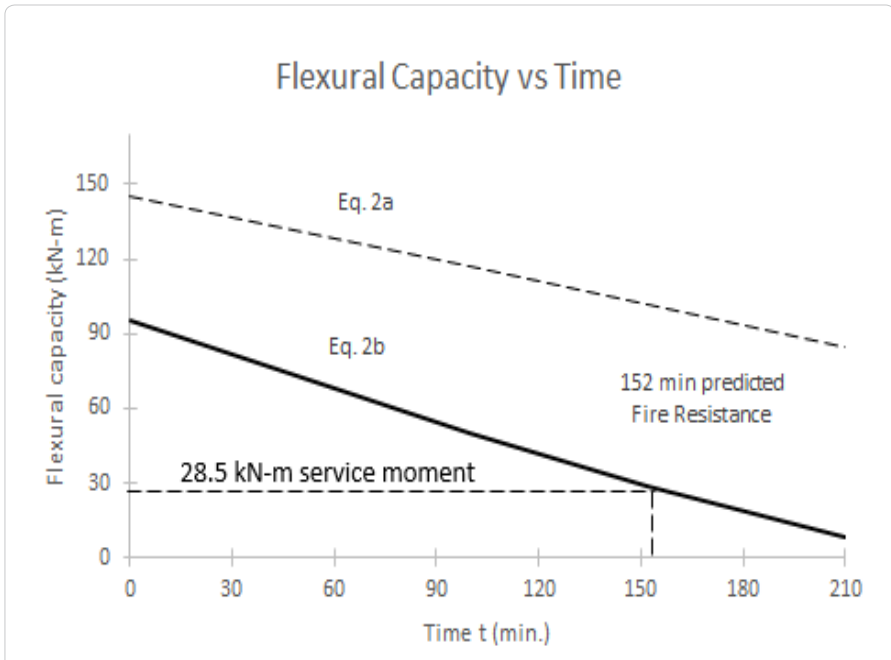

Figure 2: Flexural capacity with respect to time using equations $2 \mathrm{a}$ and $2 \mathrm{~b}$.

within $20 \%$ of the actual failure time of 128 minutes obtained through experimentation.

\section{Conclusion and Further Research}

The model to predict failure time of FRP reinforced concrete beams under elevated temperatures was applied to a previously tested beam configuration. The beam was tested to failure under fire conditions and provided a reinforcement configuration that isolated the flexural capacity of the FRP reinforced beam. The previously tested model reported that the beam failed after 128 minutes of exposure to fire. Our model suggested that under the same loading and fire conditions, the FRP reinforced concrete beam experienced failure at 152 minutes. The result is within $20 \%$ of the time obtained through experimentation. This suggests that the model, if applied in design, would be less conservative.

There are limited sources that provide reduction factors that reflect the changing modulus of elasticity of FRP as its exposure time to high temperatures increases. Without extensive and reliable experimentation, it is difficult to know how the mechanical properties of FRP change with time when it is exposed to high temperatures. The thickness of the concrete cover directly affects the failure time, and makes examining the properties of FRP more difficult. This suggests more investigation into the heat transmissibility of concrete considering different concrete mixes.

The model in this work has been applied to rectangular beams, further investigation into the application of such a model for FRP reinforced concrete slabs may also be considered in the future. The glass transition temperature of the FRP reinforcement is the limiting temperature of the material. As the temperature increases beyond that limit, the FRP is no longer serviceable. Therefore, further investigation into the possibility of increasing that limiting temperature by changes in the composition of the resin would create a topic of special interest, and be of great worth.

\section{References}

1. Nadjai A, Talamona D, Ali F, (2005) Fire performance of concrete beams reinforced with FRP bars. In: Proceedings of the First International Symposium on Bond Behavior of FRP in Structures, BBFS, Hong Kong. pp: 401-410.

2. Nanni $A(2005)$ Guide for the design and construction of concrete reinforced with FRP bars (ACl 440.1R-03), Structures Congress pp: 1-45.

3. Canadian Standards Association (2002) Design and construction of building components with fiber-reinforced polymer, CSA. 
4. Soudki K, Alkhrdaji T (2005) Guide for the design and construction of externally bonded FRP systems for strengthening concrete structures ( $\mathrm{ACl} 440.2 \mathrm{R}-02$ ). Structures Congress.

5. British Standards Institution (1987) Fire tests on building materials and structures: Method of determination of fire resistance of elements of construction. BS 476: BSI British Standards.

6. British Standards Institution (2008) Code of practice for fire safety in the design, management and use of buildings. BS 9999: BSI British Standards.

7. Blontrock, H, Taerwe L, Matthys S (1999) Properties of fiber-reinforced plastics at elevated temperatures with regard to fire resistance of reinforced concrete members. ACI. 188: 43-45.

8. Bank LC (1993) Properties of FRP reinforcements for concrete. FRPRCS. Elsevier. pp: 59-86.

9. Bakis CE (1993) FRP reinforcement: Material and Manufacturing. FRPRCS. Elsevier. pp: 13-58.

10. Wang YC, Wong PMH, Kodur VK (2003) Mechanical properties of fiber reinforced polymer reinforcing bars at elevated temperatures. InSFPE/ASCE
Specialty Conference: Designing Structures for Fire, Baltimore, Maryland. pp: 183-192.

11. Abbasi A, Hogg PJ (2005) Temperature and environmental effects on glass fibre rebar: Modulus, Strength and interfacial Bond Strength with concrete. Composites Part B. 36: 394-404.

12. NEFCOM Corporation, Technical Leaflet 3,"Fire Resistance of Concrete Slabs Reinforced by NEFMAC", NEFCOM Corporation, Tokyo, Japan.

13. ACl Committee (2008) Building code requirements for structural concrete (AC 318-08) and commentary. American Concrete Institute, USA.

14. Abbasi A, Hogg PJ (2005) Prediction of the failure time of glass fiber reinforced plastic reinforced concrete beams under fire conditions. J. Compos Constr. 9 : 450-457.

15. Bailey C (2002) Holistic behavior of concrete buildings in fire. structures buildings. 152: 199-212.

16. Abbasi A, Hogg PJ (2004) Fire testing of concrete beams with fibre reinforced plastic rebar. Advanced Polymer Composites for Structural Applications in Construction. pp: 445-456. 